\title{
Scopolamine and Pavlovian Fear Conditioning in Rats: Dose-Effect Analysis
}

\author{
Stephan G. Anagnostaras, Ph.D., Stephen Maren, Ph.D., Jennifer R. Sage, M.A., \\ Stacy Goodrich, B.A., and Michael S. Fanselow, Ph.D.
}

\begin{abstract}
Muscarinic-cholinergic antagonism produces learning and memory deficits in a wide variety of hippocampal-dependent tasks. Hippocampal lesions produce both acquisition deficits and retrograde amnesia of contextual fear (fear of the place of conditioning), but do not impact fear conditioning to discrete cues (such as a tone). In order to examine the effects of muscarinic antagonism in this paradigm, rats were given 0.01 to $100 \mathrm{mg} / \mathrm{kg}$ of scopolamine (or methylscopolamine) either before or after a fear conditioning session in which tones were paired with aversive footshocks. Fear to the context and the tone were assessed by measuring freezing in separate tests. It was found that pretraining, but not posttraining, scopolamine severely impaired fear conditioning;
\end{abstract}

methylscopolamine was ineffective in disrupting conditioning. Although contextual fear conditioning was more sensitive to cholinergic disruption, high doses of scopolamine also disrupted tone conditioning. Scopolamine did not affect footshock reactivity, but did produce high levels of activity. However, hyperactivity was not directly responsible for deficits in conditioning. It was concluded that scopolamine disrupts CS-US association formation or CS processing, perhaps through an attenuation of hippocampal theta rhythm.

[Neuropsychopharmacology 21:731-744, 1999] (C) 1999 American College of Neuropsychopharmacology. Published by Elsevier Science Inc.
KEY WORDS: Muscarinic cholinergic; Learning; Consolidation; Freezing; Analgesia; Activity; Theta

Cholinergic neurotransmission is known to be essential for many forms of learning. Using muscarinic receptor antagonists (scopolamine or atropine), pervasive impairments of learning have been demonstrated in humans (Crow and Grove-White 1973), monkeys (Aigner et al. 1991), rabbits (Harvey et al. 1983, and rodents (Levin et al. 1990). In many behavioral paradigms, the deficits produced by muscarinic-cholinergic antagonism are similar to the effects produced by hippocam-

From the Department of Psychology and Brain Research Institute (SGA, JRS, SG, MSF), University of California, Los Angeles, CA; and Department of Psychology and Neuroscience Program (SM), University of Michigan, Ann Arbor, MI.

Address correspondence to: Stephan Anagnostaras, Ph.D., UCLA Dept. of Psychology, 1285 Franz Hall, Los Angeles, CA 90095-1563. pal lesions (Watts et al. 1981; Anagnostaras et al. 1995), while in others they are more general (Hagan et al. 1986; Rudy 1996; Paylor and Rudy 1990). Although the precise mechanism for muscarinic antagonistic effects on memory is unknown, it may involve the disruption of hippocampal theta rhythm, which is normally activated during exploratory behavior (Vanderwolf et al. 1978), and the attenuation of hippocampal long-term potentiation (LTP) (Huerta and Lisman 1995).

Recent studies indicate that the hippocampus has an important role in Pavlovian fear conditioning. During fear conditioning, a discrete conditional stimulus (CS; often a tone) is paired with an aversive unconditional stimulus (US; often an electrical footshock) in a novel context. With repeated pairings, the animal learns to fear both the tone and the training context. Hippocampal lesions produce an acquisition deficit (Phillips and LeDoux 1992; Maren and Fanselow 1997) and a timelimited retrograde amnesia (Kim and Fanselow 1992; Anagnostaras et al. 1999) that is selective for contextual 
fear. The acquisition of contextual fear also seems to depend on the induction of hippocampal LTP, as NMDA receptor blockade prior to, but not after, conditioning disrupts the acquisition of contextual fear (Kim et al. 1991; Fanselow et al. 1994; Young et al. 1994; Maren et al. 1996b). Moreover, there is a high correspondence between hippocampal theta rhythm and the acquisition of contextual fear (Maren et al. 1994a). Thus, because the hippocampus receives intensive cholinergic input from the medial septal nucleus (Amaral and Kurz 1985), one would expect that muscarinic-cholinergic antagonism should disrupt contextual fear acquisition, at least to the extent that anticholinergic action can attenuate hippocampal function.

Consistent with this view, we recently reported a large, but selective deficit in contextual fear conditioning when $1 \mathrm{mg} / \mathrm{kg}$ of scopolamine was administered prior to conditioning (Anagnostaras et al. 1995). Tone fear conditioning, which is typically intact in animals with hippocampal dysfunction (Kim and Fanselow 1992; Phillips and LeDoux 1992), but readily disrupted by manipulations directed at the amygdala (Maren et al. 1996a; Davis 1986), was mildly but nonsignificantly impaired (Anagnostaras et al. 1995). Because the amygdala receives cholinergic innervation from the nucleus basalis magnocellularis a milder amygdala impairment may have been present as well. Consistent with our findings, Rudy (1996) has found that the same dose of scopolamine administered to juvenile rats (23day-old) disrupted contextual fear more than acoustic cue fear (although acoustic cue fear was also significantly disrupted) when given prior to conditioning. However, Rudy also found that post-training scopolamine produced retrograde amnesia of contextual fear, while we failed to observe this effect.

Based on these observations, we sought to examine the following hypotheses: 1) both context and tone fear conditioning may be sensitive to cholinergic disruption, but contextual fear is more readily and more robustly disrupted (i.e., the dose-effect curve is shifted to the left); and 2) the very young rats Rudy used may have exhibited retrograde amnesia from post-training scopolamine either because cholinergic neurotransmission is required for consolidation only during maturation or because they are more sensitive to the drug. As such, we became motivated to generate a full dose-effect curve for the effect of pre-training scopolamine on Pavlovian fear conditioning and to examine the effects of higher post-training doses in weanling and mature rats. Moreover, we sought to more thoroughly characterize the behavioral effects of scopolamine on Pavlovian fear conditioning through measurements of several aspects of conditioning. Through behavioral specification of the pattern of deficits produced by the drug, we hope to determine the aspects of learning or memory that scopolamine disrupts.

\section{METHODS}

\section{Common to All Experiments}

Drugs. Scopolamine- $\mathrm{HBr}$ (scopolamine; Research Biochemicals International, Natick, MA) or scopolamine methyl-Br (methylscopolamine; Sigma Chemical Co., St. Louis, MO) was prepared fresh daily in cold $0.9 \%$ saline and stored in a light-proof container. Unless otherwise noted, the drugs or control saline $(0 \mathrm{mg} / \mathrm{kg})$ were given in doses of $1 \mathrm{ml} / \mathrm{kg}$, i.p. and the weight of the salt was designated for each dose.

Contexts. The training and context test environment consisted of aluminum (side walls) and Plexiglas (front, back, and top) chambers ( $28 \mathrm{~cm}$ wide, $21 \mathrm{~cm}$ high, and $22 \mathrm{~cm}$ in diameter; Lafayette Instruments, Lafayette, IN). The floor of each chamber had 18 stainless steel rods $(0.4 \mathrm{~cm}$ in diameter, $1.5 \mathrm{~cm}$ apart) connected to a shock scrambler and generator (which, along with internal ventilation fans, supplied background noise of 70 $\mathrm{dB} / \mathrm{A}$-scale). The chambers were cleaned with $5 \%$ ammonium hydroxide solution (in collection pans below the rods). These computer-controlled (Med Associates Inc., Lafayette, IN) chambers were in a well-lit room separate from the observers, who viewed the animals on video screens, and were blind to the experimental conditions.

Tones were presented from a speaker in the wall of each chamber. The tone test context was in a separate room. These chambers (same as above) had a white rear wall inserted and two white plastic side walls $(24 \times 21$ $\mathrm{cm})$ placed at $60^{\circ}$ to the floor forming a triangular enclosure. The floors consisted of 17 staggered rods (two rows $1 \mathrm{~cm}$ apart vertically; in each row, each rod $2.6 \mathrm{~cm}$ apart). Background noise (70 dB) was supplied by a white noise generator and the chambers were scented with $1 \%$ acetic acid solution. This room was kept entirely dark except for a $30 \mathrm{~W}$ red light bulb. The carriers used to transport the animals to this context were also different than before. Our previous and current experience is that animals show little generalization between these contexts, which are differentiated on the basis of several local and distal spatial cues.

Freezing. Freezing, an established index of conditional fear in the rat, was defined as the absence of any visible movement (including the vibrissae) except that required for respiration (only fluctuation in the volume of the thorax). It was scored according to a blind instantaneous 8-sec time-sampling procedure, in which each animal was observed eight times per 64-s interval, and these were averaged to yield an estimate of the percent time freezing. Prior study has revealed that this measure is highly amenable to parametric analysis (Fanselow and Bolles 1979). 


\section{Experiment 1: The Effect of Pretraining Scopolamine on Fear Conditioning}

In Experiment 1, animals were given a logarithmically varied series of doses from 0.01 to $100 \mathrm{mg} / \mathrm{kg}$ of scopolamine. These doses were chosen because our survey of the literature suggested that $0.01 \mathrm{mg} / \mathrm{kg}$ was well below that which has been reported to produce a learning deficit in rats, and $100 \mathrm{mg} / \mathrm{kg}$ is the highest safe dose ( $\mathrm{LD}_{50, \text { i.p. }}>3000 \mathrm{mg} / \mathrm{kg}$; Research Biochemicals International, product literature), completing a logarithmic scale which would allow us to calculate median doses for the disruption of conditioning. No animals appeared to suffer ill health from any of the doses given.

Subjects. Ninety female Long-Evans rats (250-300 g, 90-110 days) bred at UCLA (Blue-Spruce stock; Harlan Sprague-Dawley Inc., San Diego, CA) were used in this experiment. They were housed in individual metal cages located in a colony maintained on a 14:10 light:dark cycle. They had unrestricted access to dry food and water and were handled briefly prior to testing. Two animals were excluded because of equipment failure.

Training. Fifteen min prior to conditioning, animals were given 0 (saline control; $n=15), 0.01(n=15), 0.1$ $(n=14), 1(n=15), 10(n=14)$, or $100(n=15) \mathrm{mg} / \mathrm{kg}$ scopolamine, i.p. They were then placed into the conditioning chambers, and after a 3-min baseline period, the animals received five tone $(30 \mathrm{sec}, 2 \mathrm{kHz}, 85 \mathrm{~dB} / \mathrm{A}$ scale)-shock ( $2 \mathrm{sec}, 1 \mathrm{~mA}$ ) pairings, with each pairing separated by $64 \mathrm{sec}$ each. One min after the last shock, the animals were returned to their home cages. Freezing was scored continuously over the 12 -min training period.

Generalized Activity. In order to assess activity produced by scopolamine on the training day, horizontal activity was assessed during the 3-min baseline period prior to the first shock. Cage-crossovers were scored from videotape by blind observers, and defined as full crossing of both the fore and hind paws across the midpoint of each cage (designated by a black vertical stripe placed on the video monitors).

Activity Burst Assessment. In order to determine if scopolamine attenuated reaction to the aversive footshock, we assessed the velocity of the visible unconditional response (UR) to the first shock during conditioning. We have recently validated this new measure of the UR, demonstrating that it has a highly sensitive shock intensity function (Godsil et al. 1997).

Each animal's response during the first 2-sec footshock was digitized from videotape at $10 \mathrm{~Hz}(20$ frames) with NIH Image (v. 1.6.1; National Institutes of Health, Bethesda, MD) using the built-in digitizer on an Apple Macintosh 8500/180 (Apple Computer Inc., Cu- pertino, CA) and compared with the 2-sec baseline period immediately prior to the footshock. For each frame, a blind observer clicked on the location of the rat and $x-y$ coordinates were recorded by Image using the wand auto-measure tool. This data was imported into Microsoft Excel (Microsoft Corp., Redmond, WA) and distance traveled between each frame in pixels was computed using the distance formula, $\sqrt{ }\left[\left(x_{n}-x_{n+1}\right)^{2}+\right.$ $\left.\left(y_{n}-y_{n+1}\right)^{2}\right]$; pixels traveled was then converted into $\mathrm{cm}$ traveled based on known landmarks in the picture frame (the box dimensions).

Finally, this was divided by time and averaged over the 2-sec period to yield the animal's mean velocity in $\mathrm{cm} / \mathrm{sec}$ separately for the 2-sec baseline and 2-sec shock period. Although other indexes of movement intensity can be taken, prior work indicates that velocity has the most sensitive shock-intensity function and is a good predictor of later conditioning in the range of shocks we typically use in fear conditioning (Godsil et al. 1997). For convergent validity, we used a more traditional measure of pain sensitivity in Experiment 3, however, we favor UR velocity, because it is an actual measure of the rat's UR to a shock it received during conditioning. In either case, for the present study both measures yielded equivalent findings.

Tests for Conditioning. In order to allow for drug clearance and the resumption of a normal sleep-wake cycle, the animals were allowed to rest for one week. Eight days after conditioning, all animals were placed back into the original training context for a 4-min, offdrug context test. Freezing behavior was scored continuously. One day later the animals were brought to a novel context (above) for a 6-min tone test. The animals were placed in this context and after a 2-min baseline the conditioning tone (as before) was presented for $4 \mathrm{~min}$.

\section{Experiment 2: The effect of Pre-Training Methylscopolamine on Fear Conditioning}

In order to determine if the effects of scopolamine observed in Experiment 1 were due to action in the central nervous system, we examined the effect of pre-training methylscopolamine, which does not cross the bloodbrain barrier but remains active peripherally (Brown 1993).

Subjects. Thirty female Long-Evans rats (250-300 g, 90-110 days) bred at UCLA were used in this experiment (as before). One animal was excluded as a result of equipment failure.

Training. Fifteen min prior to conditioning, animals received either $0(n=9), 1(n=10)$, or $10(n=10) \mathrm{mg} /$ $\mathrm{kg}$ methylscopolamine, i.p. Conditioning was under the same conditions as in Experiment 1. Both 1 and $10 \mathrm{mg} /$ 
$\mathrm{kg}$ of scopolamine produced substantial impairments in contextual fear conditioning in Experiment 1.

Testing. All testing was done as in Experiment 1, although given the absence of any effect of scopolamine, the UR was not examined in Experiment 2. Post-shock freezing was also not examined, but activity during training, and context and tone conditioning 8-9 days after training were all assessed under conditions identical to Experiment 1.

\section{Experiment 3: Scopolamine and Shock-Intensity Thresholds}

In order to obtain convergent validity with our novel UR measure from Experiment 1, we employed a traditional method of examining shock sensitivity in rats. A naive set of animals had to be used, and they were given a series of incremental ascending shocks while their thresholds for making a flinch, jump, or vocalization response (usually in that order) were noted.

Subjects. Eighteen female Long-Evans rats (250-300 g, 90-110 days) bred at UCLA were used in this experiment (as before).

Flinch-Jump-Vocalization Threshold Testing. Fifteen min prior to testing, the animals received 0,1 , or 100 $\mathrm{mg} / \mathrm{kg}$ scopolamine, i.p. $(n=6 /$ dose $)$. The animals were then transported to the laboratory and immediately placed into conditioning chambers. Each animal received two ascending series of 2 -sec shocks in 0.05 $\mathrm{mA}$ increments (beginning from 0 ), each shock $10 \mathrm{sec}$ apart.

A blind observer noted the first instance of a flinch (defined as any noticeable reaction, most often a head jerk), jump (defined as any of the animal's paws leaving the grid floor), or vocalization (defined as any audible squeal) response. As soon as all three responses were observed in a given series, the next series began at 0 $\mathrm{mA}$. Shocks greater than $0.8 \mathrm{~mA}$ were never needed. Two observations each for flinch, jump, and vocalize were averaged to generate thresholds for each rat.

\section{Experiment 4: The Effect of Post-Training Scopolamine on Fear Conditioning}

In order to determine if a higher dose of scopolamine than we previously used (Anagnostaras et al. 1995) could produce retrograde amnesia in adult rats, a high dose $(10 \mathrm{mg} / \mathrm{kg})$ was administered either immediately or 1 day after training.

Subjects. Thirty male Long-Evans rats (300-400 g, 90110 days) bred at UCLA were used in this experiment (as before). One animal was excluded as a result of equipment failure.
Training. Conditioning was identical to Experiments 1 and 2, except for the following differences: 1) because male rats, which condition more rapidly than female rats (Maren et al. 1994b), were used, three instead of five tone-shock pairings were given; and 2) the animals were divided into three groups: Immediate $(n=10)$-animals received $10 \mathrm{mg} / \mathrm{kg}$ scopolamine, i.p., immediately after training and saline $24 \mathrm{hrs}$ later; Delay $(n=9)$ animals received saline immediately after training and $10 \mathrm{mg} / \mathrm{kg}$ scopolamine, i.p., $24 \mathrm{hrs}$ after training; finally, saline Control $(n=10)$-animals were given saline immediately after training and $24 \mathrm{hrs}$ later. After training, great care was taken so that all animals received the injections within 2 min of the last shock.

Testing. Because animals were not on drug until after training, activity, UR, and post-shock freezing were not assessed during training. Eight to nine days after conditioning, context and tone conditioning were assessed as before.

\section{Experiment 5: The Effect of Post-Training Scopolamine on Fear Conditioning in Juvenile and Mature Rats}

In order to determine if post-training scopolamine would produce retrograde amnesia in weanling rats because they may be more sensitive to the drug (e.g., Paylor and Rudy 1990; Rudy 1996; Anagnostaras et al. 1995), the effect of 1 and $50 \mathrm{mg} / \mathrm{kg}$ of post-training scopolamine was examined in animals the same age as those Rudy (1996) used and in mature rats. In order to accommodate the juvenile animals, several procedural modifications were made (noted below).

Subjects. Thirty-four Juvenile (20-25 days, 35-60 g) and 38 Mature (70-75 days, 175-225g) female LongEvans rats bred at UCLA were used. The animals were housed in groups of 2-3 (segregated by age) and had unrestricted access to a wet mash rat chow and water.

Contexts. The contexts were as before, except for the following modifications (used for all animals): 1) the rod floors in the training and context test context were replaced with ones that were thinner and more tightly spaced (24 rods, $0.2 \mathrm{~cm}$ in diameter, $1 \mathrm{~cm}$ apart); and 2) flat Plexiglas inserts were placed into the tone test context to form a floor that the juvenile animals could not escape through.

Training. After being transported to the laboratory, the animals were placed into the conditioning chambers, and after a 2-min baseline period, received three tone ( $20 \mathrm{sec}, 80-\mathrm{dB} / \mathrm{A}$ scale)-shock (2 sec, $1 \mathrm{~mA}$ ) pairings, with each pairing separated by $2 \mathrm{~min}$ [these parameters were taken from Rudy (1996), Experiment 5, although he used a clicker CS instead of a tone]. 
Juvenile and Mature rats were divided into three subgroups, which received either 0 (saline control; juvenile $n=12$; mature $n=13$ ), 1 (juvenile $n=11$; mature $n=$ 13 ), or 50 (juvenile $n=11$; mature $n=12$ ) $\mathrm{mg} / \mathrm{kg}$ scopolamine $(2 \mathrm{ml} / \mathrm{kg}$, i.p.) immediately after training. Great care was taken so that all animals received injections within 2-min of the last tone-shock pairing.

Testing. Because animals were not on drug until after training, activity, UR, and post-shock freezing were not assessed. Eight to nine days after conditioning, context and tone testing were done as before.
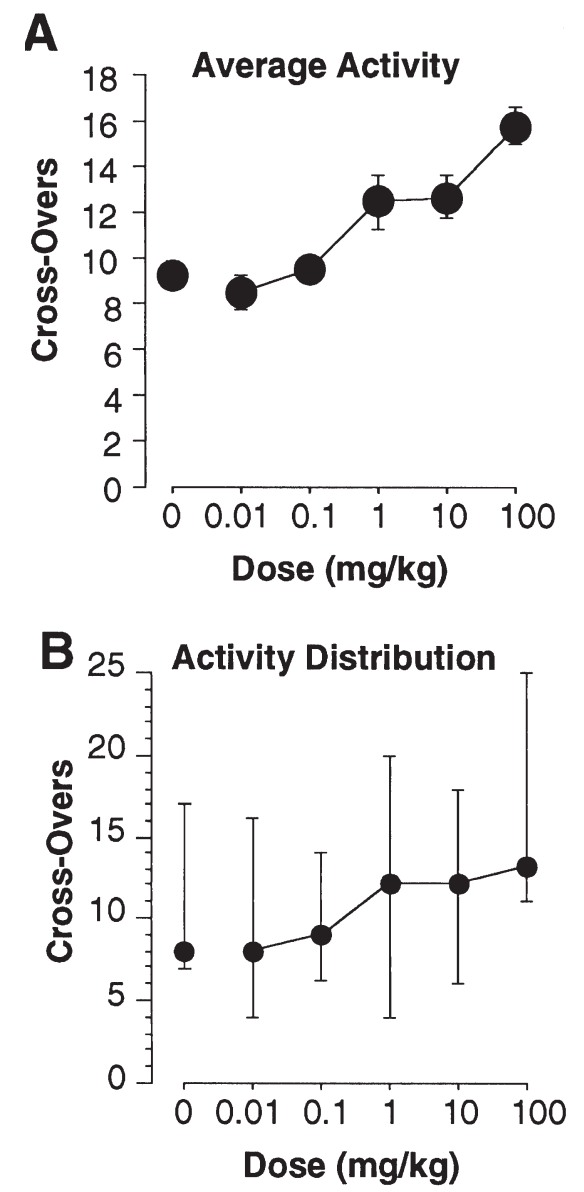

Figure 1. Experiment 1: The effect of Pre-Training Scopolamine on Fear Conditioning. (A) Average Activity. During the 3-min baseline period prior to the first shock on the conditioning day, full cage-crossovers (mean \pm SEM) were assessed. Animals that received 1, 10, or $100 \mathrm{mg} / \mathrm{kg}$ scopolamine, i.p., 15 min earlier showed marked hyperactivity relative to saline controls $(0 \mathrm{mg} / \mathrm{kg})$, whereas those that received 0.1 or $0.01 \mathrm{mg} / \mathrm{kg}$ did not ( $n=14-15 /$ group). (B) Activity Distribution. The distribution of cage-crossovers (median \pm range) are depicted. Although 1, 10, and $100 \mathrm{mg} /$ $\mathrm{kg}$ increased average activity, the distribution of activity primarily overlapped; even at $100 \mathrm{mg} / \mathrm{kg}$ only two out of 15 animals were outside of the range of that of saline controls.

\section{RESULTS}

\section{Experiment 1: The Effect of Pretraining Scopolamine on Fear Conditioning}

Generalized Activity. As can be seen in Figure 1A, scopolamine produced a large dose-dependent increase in cage cross-overs during the 3-min baseline period on the training day. A univariate analysis of variance (ANOVA) confirmed group differences $[F(5,82)=10.7$, $p<.0001]$. Relative to saline control animals, 1, 10, and $100 \mathrm{mg} / \mathrm{kg}$ of scopolamine produced significant hyperactivity (Fischer's protected least significant differences (PLSD), multiple post-hoc comparisons, $p<.01$ ), but 0.01 or $0.1 \mathrm{mg} / \mathrm{kg}(p>.5)$ did not. Moderate to high doses of the drug $(1,10$, or $100 \mathrm{mg} / \mathrm{kg})$ increased activity, on average, $30-80 \%$.

On the other hand, Figure 1B shows the distribution of cage crossovers (median and range). Although there is a large increase in average activity, even at $100 \mathrm{mg}$ / $\mathrm{kg}$ only two out of 15 animals were outside of the range of that of saline control animals. These findings are consistent with many prior reports of hyperlocomotion in scopolamine-treated animals (see Mathur et al. 1997 for an analysis).

Activity Burst Velocity. Scopolamine had virtually no impact on the visible unconditional response to shock at any dose (Table 1A, Experiment 1). The drug doses did not differ in terms of activity burst velocity whether baseline was subtracted or not [separate ANOVAs, $F(5,82)<0.2, p>$.9]. All groups exhibited a massive increase in velocity during the shock [separate paired two-tailed $t$-tests for each dose, baseline vs. shock: $t(13-$ 14) $>10, p<.0001]$.

Post-Shock Freezing. Figures $2 \mathrm{~A}$ and $2 \mathrm{~B}$ visually depict the effect of scopolamine on freezing observed during the training day, on drug. Figure 2A depicts the acquisition of post-shock freezing. For baseline, freezing during the 3-min baseline and first 30 -sec tone is depicted. For each trial $(94 \mathrm{sec})$, freezing during shockfree period after that shock and during the next 30-s tone prior to the next shock is depicted. Saline control (0) animals showed evidence of acquisition of postshock freezing [paired two-tailed $t$-test, BL vs. trial 4 , $t(14)=9.3, p<.0001)]$ as did animals receiving 0.01 $[t(14)=8.8, p<.0001], 0.1[t(13)=5.6, p<.0001]$, and 1 $[t(14)=2.8, p=.01] \mathrm{mg} / \mathrm{kg}$, whereas those receiving 10 or $100 \mathrm{mg} / \mathrm{kg}$ hardly exhibited any freezing and did not show significant acquisition [ $t(13-14)<1.8, p>.1]$. Indeed, over three quarters of the animals in these two groups did not exhibit any post-shock freezing at all. Figure 2B depicts the average freezing observed during training separated for periods when the tone was on compound and for when it was not context alone. Unambiguous dose-dependent effects on post-shock freezing 
Table 1. Pain Sensitivity in Scopolamine-Treated Rats

\begin{tabular}{|c|c|c|c|c|c|c|}
\hline \multicolumn{3}{|c|}{ A. Experiment 1: Shock Reactivity } & \multicolumn{4}{|c|}{ B. Experiment 3: Pain Sensitivity Thresholds } \\
\hline Dose $(\mathrm{mg} / \mathrm{kg})$ & Baseline $(\mathrm{cm} / \mathrm{s})$ & Shock $(\mathrm{cm} / \mathrm{s})$ & Dose (mg/kg) & Flinch (mA) & Jump (mA) & Vocalize (mA) \\
\hline 0 & $3.7 \pm 0.3$ & $54.0 \pm 4.0$ & 0 & $0.18 \pm 0.02$ & $0.18 \pm 0.01$ & $0.18 \pm 0.01$ \\
\hline 0.01 & $3.2 \pm 0.5$ & $54.0 \pm 4.1$ & 1 & $0.34 \pm 0.05$ & $0.31 \pm 0.03$ & $0.32 \pm 0.03$ \\
\hline 0.1 & $3.3 \pm 0.4$ & $53.8 \pm 3.8$ & 100 & $0.54 \pm 0.02$ & $0.52 \pm 0.04$ & $0.47 \pm 0.07$ \\
\hline 1 & $3.5 \pm 0.4$ & $55.7 \pm 3.3$ & & & & \\
\hline 10 & $3.3 \pm 0.3$ & $52.0 \pm 4.8$ & & & & \\
\hline 100 & $4.0 \pm 0.3$ & $51.8 \pm 4.5$ & & & & \\
\hline
\end{tabular}

Shock reactivity after treatment with scopolamine was assessed according to two protocols. A. Experiment 1 : On the conditioning day, the 2-s period prior to (baseline) and during the first footshock was digitized by computer and the average velocity (cm/s, mean \pm SEM) was computed for each drug dose. Doses from 0.01 to $100 \mathrm{mg} / \mathrm{kg}$ of scopolamine had no measurable impact on activity burst velocity. B. Experiment 3: Naive rats were given a series of ascending footshocks until flinch, jump, and vocalize responses were observed. Threshold current (mA, mean \pm SEM) is shown. Scopolamine failed to affect pain sensitivity at any dose.

to the tone-context compound $[F(5,82)=47, p<.0001]$ or context-alone $[F(5,82)=32, p<.0001]$ are evident. Relative to saline controls, $0.01 \mathrm{mg} / \mathrm{kg}$ produced a mild elevation in freezing for both measures (Fischer's PLSD, $p<.05), 0.1$ produced no significant effects $(p>.7)$ and 1,10 , and $100 \mathrm{mg} / \mathrm{kg}$ produced large deficits in postshock freezing $(p<.0001)$.

As such, moderate to high doses of scopolamine readily and robustly disrupted post-shock freezing. This may have been produced by large increases in motor activity which may have interfered with post-shock freezing (Figure 1). In order to address this issue, we performed an analysis of covariance (ANCOVA) in which each animal's activity score was treated as a covariate. Even when the variance attributable to differences in activity was covaried out, significant differences in both post-shock freezing measures remained [context-alone, $F(1,81)=16, p<.0001$; compound, $F(1,81)=25, p<.0001$; significant post-hoc comparisons remained as before]. Therefore hyperactivity may contribute to the deficit in post-shock freezing, but at most can only partially account for the massive impairment observed. One alternative interpretation is that post-shock freezing deficits observed on-drug were due to disruption of short-term working memory processes that post-shock freezing is thought to depend on (e.g., Levin et al. 1990). Indeed, by one view, a working memory impairment could actually support hyperactivity by generating abnormal exploratory patterns which may not show normal habituation (e.g., Maren et al. 1998). Alternatively, both short-term memory impairment and hyperactivity together may have contributed to this robust and nearly complete impairment.

Additionally, the post-shock freezing data also tend to suggest that scopolamine's deficits on later conditioning (tested off-drug) are not due to state-dependency (e.g., Overton, 1966), as the deficits observed on the drug are substantially greater than those observed when the rats are tested off drug (see below). The statedependency view would likely predict the reverse.
Context Fear. One week after receiving scopolamine during training, the animals were returned to the original training environment for an off-drug contextual fear test. Figure 3A depicts the average freezing observed during the 4-min test. Scopolamine produced dosedependent deficits in contextual fear conditioning [ANOVA, $F(5,82)=11.4, p<.0001]$. Fischer's PLSD post-hoc comparisons revealed that, relative to saline control animals, $1(p<.05), 10(p<.001)$, and $100(p<$ $.0001) \mathrm{mg} / \mathrm{kg}$ produced progressively large deficits, whereas 0.1 and $0.01 \mathrm{mg} / \mathrm{kg}$ did not produce significant differences $(p>.4)$. Thus scopolamine produced large deficits in contextual fear, reducing conditioning by $30-80 \%$ at doses of $1-100 \mathrm{mg} / \mathrm{kg}$; however, this was not as complete as its effect on post-shock freezing, where high doses abolished freezing altogether.

Tone Fear. One day after the contextual fear test, animals were brought to a novel environment, and after a 2-min baseline period, the original training tone was played for $4 \mathrm{~min}$. Figure 3B depicts the results of this test. None of the animals exhibited considerable baseline freezing (data not shown) and the groups did not differ in this respect [Kruskall-Wallis ANOVA, $H(5)=$ 3.3, $p>.6]$, but scopolamine did have effects on toneelicited freezing [ANOVA, $F(5,82)=4, p<.01$ ]. Compared to saline controls, $100 \mathrm{mg} / \mathrm{kg}$ produced significant deficits $(p<.01)$, whereas despite moderate trends at 1 and $10 \mathrm{mg} / \mathrm{kg}$, these doses did not produce significant tone deficits $(p>.2)$. There was some marginal evidence that 1 and $10 \mathrm{mg} / \mathrm{kg}$ may have produced a small deficit in conditioning, as these groups did exhibit significantly lower tone fear than $0.01 \mathrm{mg} / \mathrm{kg}(p<.05)$, which did not differ significantly from saline control animals $(p>.6)$. Nonetheless, tone fear conditioning appears to be more resistant to scopolamine's effects than context conditioning or post-shock freezing.

Median Effective Dose Calculations. Based on the preceding findings, it seemed apparent that post-shock freezing (on drug) was more sensitive to disruption by 

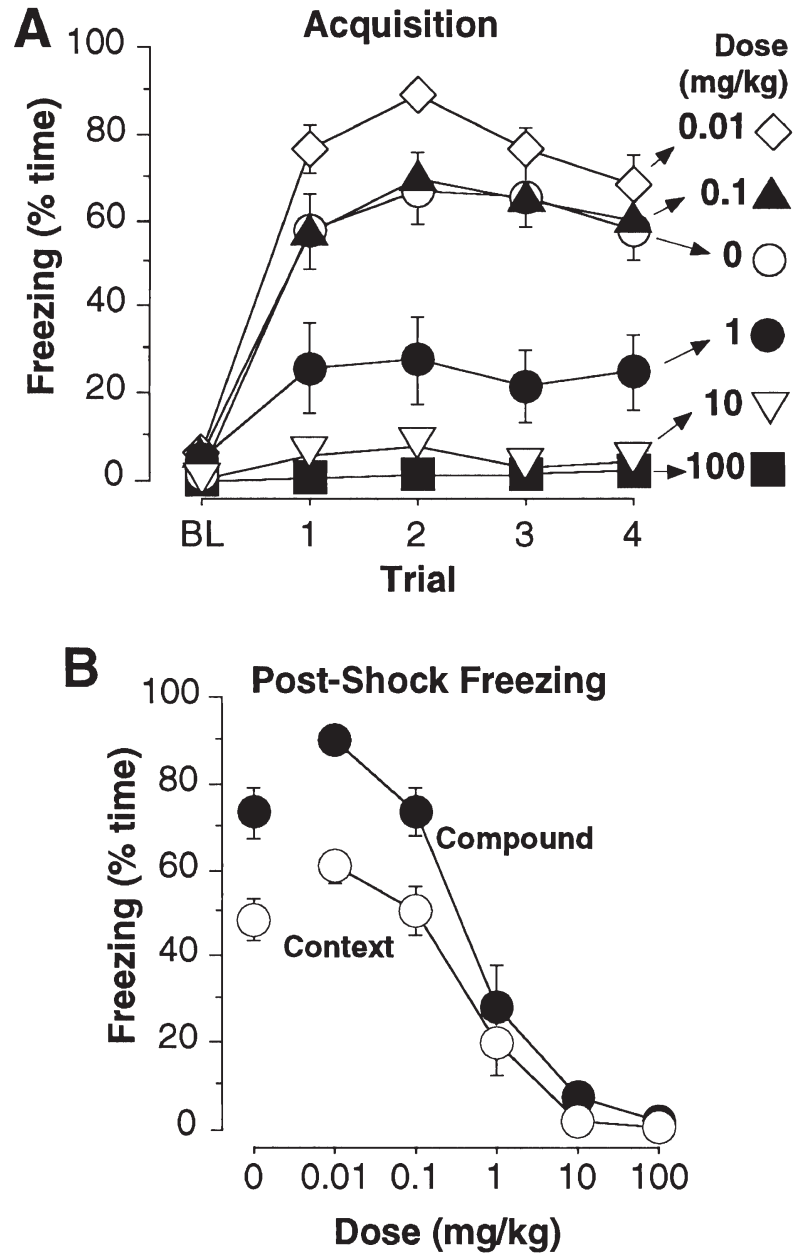

Figure 2. (A) Acquisition. During conditioning, post-shock freezing ( $\%$ time, mean \pm SEM) was assessed continuously, while the animals were on the drug. Compared to saline controls $(0 \mathrm{mg} / \mathrm{kg}), 0.01 \mathrm{mg} / \mathrm{kg}$ scopolamine slightly enhanced post-shock freezing, $0.1 \mathrm{mg} / \mathrm{kg}$ had no impact, and $1 \mathrm{mg} / \mathrm{kg}$ produced a substantial deficit (but these animals still showed significant acquisition). Ten and $100 \mathrm{mg} /$ $\mathrm{kg}$ almost completely blocked post-shock freezing, as over three-quarters of these animals never froze during training. (B) Overall Post-Shock Freezing. Overall post-shock freezing (\% time, mean \pm SEM) during conditioning was separated for periods when the tone was on (context-tone compound) or not (context alone). Compared to saline controls (0 mg/ $\mathrm{kg}), 0.01 \mathrm{mg} / \mathrm{kg}$ slightly enhanced post-shock freezing during either period, 0.1 had no significant impact, whereas 1, 10, and $100 \mathrm{mg} / \mathrm{kg}$ dramatically reduced post-shock freezing.

scopolamine than contextual fear conditioning, which was in turn more sensitive than tone fear conditioning (both tested off drug). In order to further compare them we attempted to calculate median doses for the disruption of conditioning according to the following procedure derived from Nies (1993): 1) the desired effect was defined as a one-half reduction in the response relative to the mean of saline control animals (nontrivial and also outside the normal variation of controls); as such,
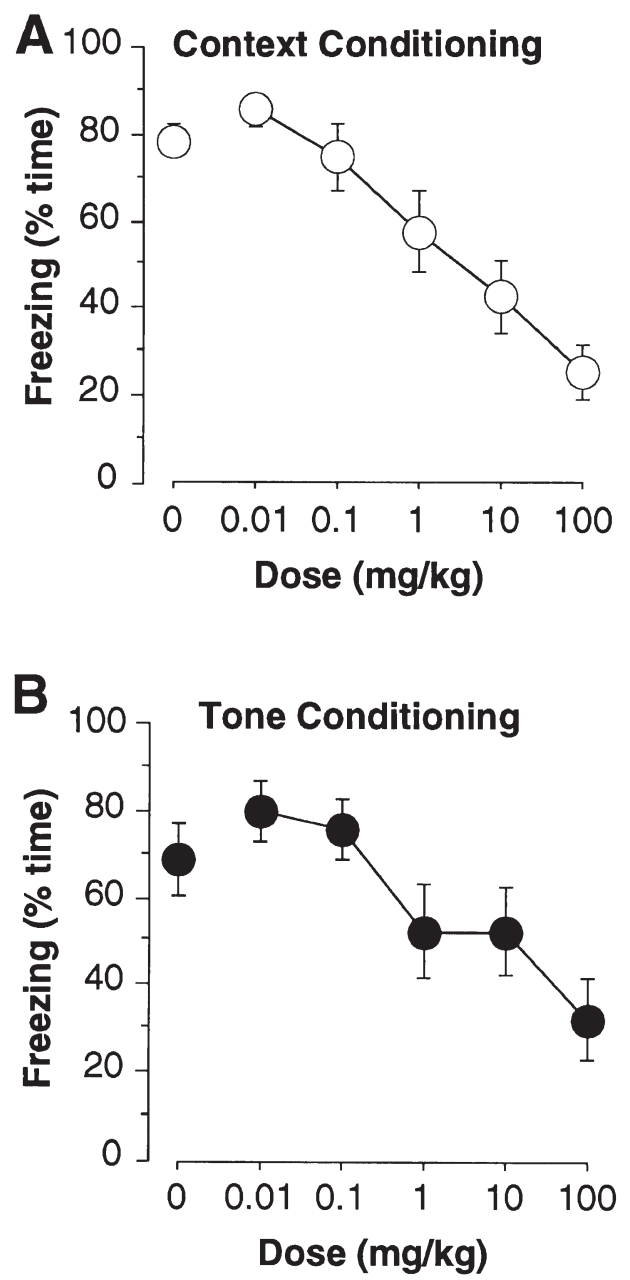

Figure 3. (A) Context Conditioning. One week after conditioning, the animals were returned to the original training context, off drug, and freezing ( $\%$ time, mean \pm SEM) was scored for $4 \mathrm{~min}$. Compared to saline controls $(0 \mathrm{mg} / \mathrm{kg}), 1$, 10 , and $100 \mathrm{mg} / \mathrm{kg}$ significantly attenuated conditioning, whereas 0.01 and $0.1 \mathrm{mg} / \mathrm{kg}$ did not. (B) Tone Conditioning. On the next day, the animals were brought to a novel context and freezing (\% time, mean \pm SEM) during the 4-min tone is depicted. Relative to controls, only $100 \mathrm{mg} / \mathrm{kg}$ significantly impaired tone conditioning, modest trends were evident at 1 and $10 \mathrm{mg} / \mathrm{kg}$. As such, tone conditioning is more resistant to disruption by scopolamine than context conditioning, which is in turn more resistant than post-shock freezing (Figure 2).

animals in each group that made less than half of the average control response were assigned a value of 1 , whereas those which made more than this were assigned a zero; 2) probability-dose curves were then generated (Figures 4A-D) and logarithmic curve fits (excluding saline controls) were made (Kaleidagraph; Synergy Software); and 3) the $\mathrm{ED}_{50} \mathrm{~s}$ were computed from the curve fit. In all cases, the curve fits were quite good, yielding $r \geqslant 0.95$. 

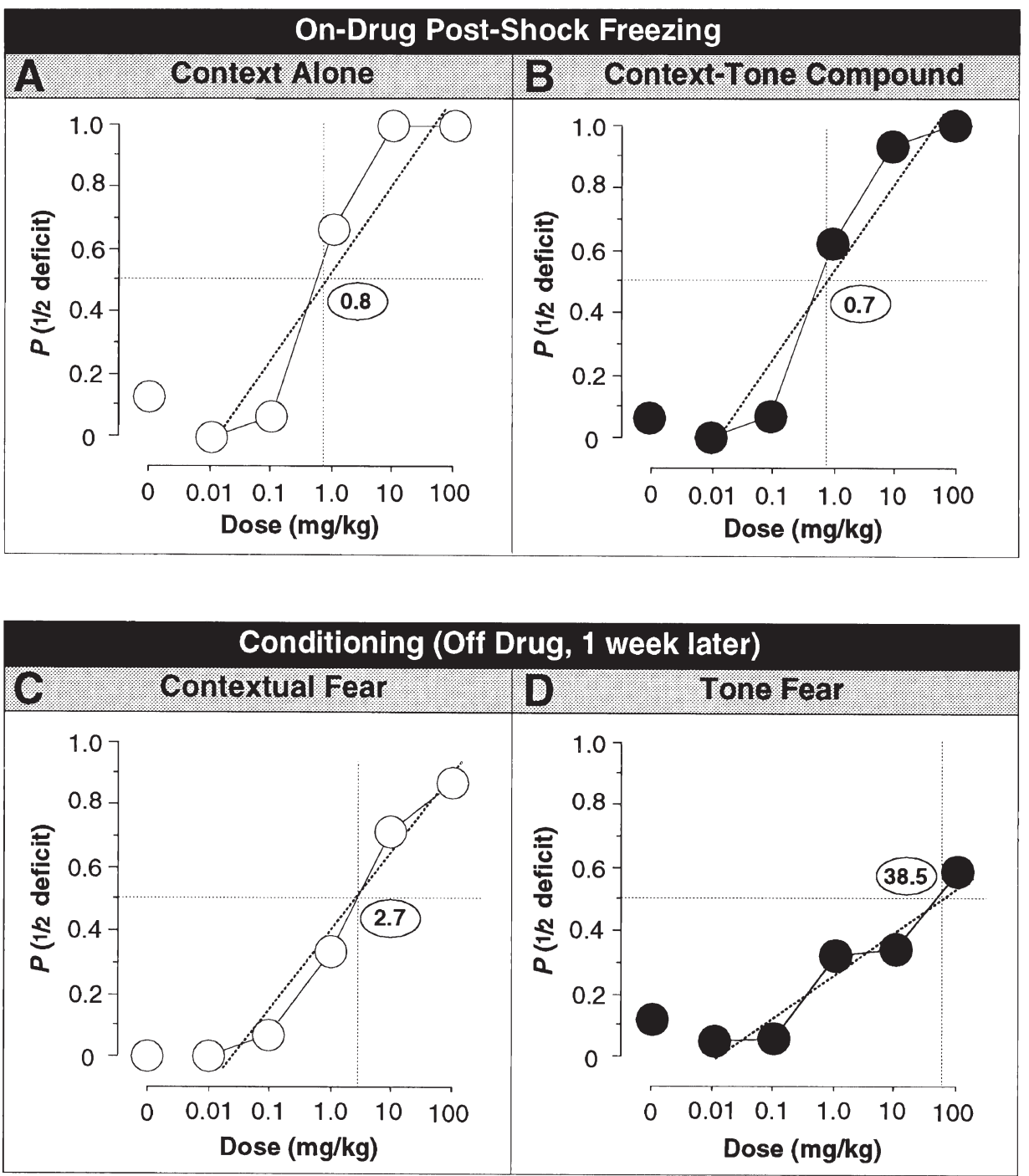

Figure 4. Experiment 1: Summary / Median Effective Dose. For each response, probabilities of obtaining a one-half reduction in conditioning (relative to the mean of saline controls) was calculated for each dose; after a logarithmic curve fit was made, median doses for each effect were calculated. (A) Post-Shock Freezing, Context-Alone. Both 10 and $100 \mathrm{mg} / \mathrm{kg}$ were sufficient to reduce post-shock freezing (taken while the animal was on-drug, during conditioning) in nearly all of the animals, whereas even $1 \mathrm{mg} / \mathrm{kg}$ had this effect in over two-thirds of the animals. The obtained curve fit $(r=0.95)$ was $\mathrm{y}=0.55+$ $0.30 \log (\mathrm{x}), \mathrm{ED}_{50}=0.8 \mathrm{mg} / \mathrm{kg}$. (B) Post-Shock Freezing, Compound. The results were substantially similar to context-alone post-shock freezing indicating these are probably the same effect of the drug. The obtained $(r=0.96)$ was $\mathrm{y}=0.52+$ $0.29 \log (\mathrm{x}), \mathrm{ED}_{50}=0.7 \mathrm{mg} / \mathrm{kg}$. (C) Context Conditioning. When the animals were tested off-drug one week later, the drug appeared to disrupt context conditioning considerably less. In contrast to post-shock freezing, even $100 \mathrm{mg} / \mathrm{kg}$ was not sufficient to disrupt conditioning in all of the animals, and $1 \mathrm{mg} / \mathrm{kg}$ reduced conditioning by half in only about one-third of the animals. The obtained curve fit $(r=0.98)$ was $\mathrm{y}=0.40+0.24 \log (\mathrm{x}), \mathrm{ED}_{50}=2.7 \mathrm{mg} / \mathrm{kg}$. (D) Tone Conditioning. Tone conditioning (tested off drug, nine days after conditioning) was even more resistant to disruption by scopolamine. Only 100 mg/ $\mathrm{kg}$ was sufficient to reduce the response by one-half and only in about 55\% of the animals. The obtained curve fit $(r=0.95)$ was $\mathrm{y}=0.29+0.14 \log (\mathrm{x}), \mathrm{ED}_{50}=38.5 \mathrm{mg} / \mathrm{kg}$. As such, tone conditioning, context conditioning, and post-shock freezing are all susceptible to anticholinergic disruption, however, they are differentially sensitive to the drug such that the disruption is post-shock $>$ context $>$ tone.

Figures 4A-B depict the probability of observing a one-half decrement in post-shock freezing relative to dose. Comparable, and low doses of scopolamine (0.7$0.8 \mathrm{mg} / \mathrm{kg}$ ) were required to attenuate post-shock freezing to either the context or context-tone compound in half the animals. The similar slopes and intercepts suggest these are mediated by the same effect of the drug. These observations are also in good agreement with the results from the ANOVAs, where doses of 1,10, and $100 \mathrm{mg} / \mathrm{kg}$ produced large and significant deficits. 
Figures 4C and D depict the dose-effect curve for the disruption of contextual and tone fear conditioning. For context, about $2.7 \mathrm{mg} / \mathrm{kg}$ was required to reduce freezing in half in one-half of the animals, whereas for tone a much higher dose, $38.5 \mathrm{mg} / \mathrm{kg}$, was required. Again, this agreed with the ANOVAs, where contextual fear was sensitive in the range of $1-100 \mathrm{mg} / \mathrm{kg}$, whereas significant deficits in tone fear were only observed at a dose of $100 \mathrm{mg} / \mathrm{kg}$. Thus, post-shock freezing (on drug) is more scopolamine-sensitive than contextual fear conditioning, which is in turn more sensitive than tone fear conditioning (both tested off drug). The dissimilar slopes for postshock freezing, context, and tone fear suggest these are dissociable actions of the drug.

Finally, although changing the definition of the desired effect (for example, to a one-third or two-thirds deficit) alters the $\mathrm{ED}_{50} \mathrm{~s}$ (lowering or raising them), it does not affect their relative positions (data not shown); that is, the deficits are always aligned such that postshock freezing $>$ context conditioning $>$ tone conditioning.

\section{Experiment 2: The Effect of Pre-Training Methylscopolamine on Fear Conditioning}

Figures 5A-C Depict the effects of pre-training methylscopolamine on generalized activity, contextual fear, and tone fear conditioning. In contrast to scopolamine, 1 or $10 \mathrm{mg} / \mathrm{kg}$ of methylscopolamine did not produce an increase in cage cross-overs during training relative to saline-treated controls [on drug; $F(2,26)=0.3, p>.7$ ], nor did it produce deficits in contextual or tone fear conditioning measured off-drug one week later [context, $F(2,26)=0.3, p>.7$; tone, $F(2,26)<0.2, p>.8$ ]. This suggests that the effects observed in Experiment 1 were due to the central rather than peripheral action of scopolamine.

\section{Experiment 3: Scopolamine and Shock-Intensity Thresholds}

For further validation of the novel UR measure used in Experiment.1, a naive set of animals were given 0,1, or $100 \mathrm{mg} / \mathrm{kg}$ scopolamine and then their thresholds to show stereotypical progressive flinch, jump, and vocalization responses were recorded. Consistent with our activity burst results (Table 1A, Experiment 1), Table 1B (Experiment 3) shows that scopolamine failed to affect shock reactivity for any response at any dose, although a very modest trend toward elevated vocalization reactivity is evident. Separate univariate ANOVAs for each response confirmed the general appearance of the numbers [flinch, $F(2,15)=0.4, p>.6$; jump, $F(2,15)=0.2$, $p>.8$; vocalize, $F(2,15)=0.4, p>.6]$.

In the present study and in Experiment 1, scopolamine failed to produce any detectable effect on pain sensitivity as measured by the animal's visible reaction to the shock during conditioning (Table 1A) or by flinch-jump-vocalization thresholds (Table 1B). This is in some disagreement with the findings of Grau et al.
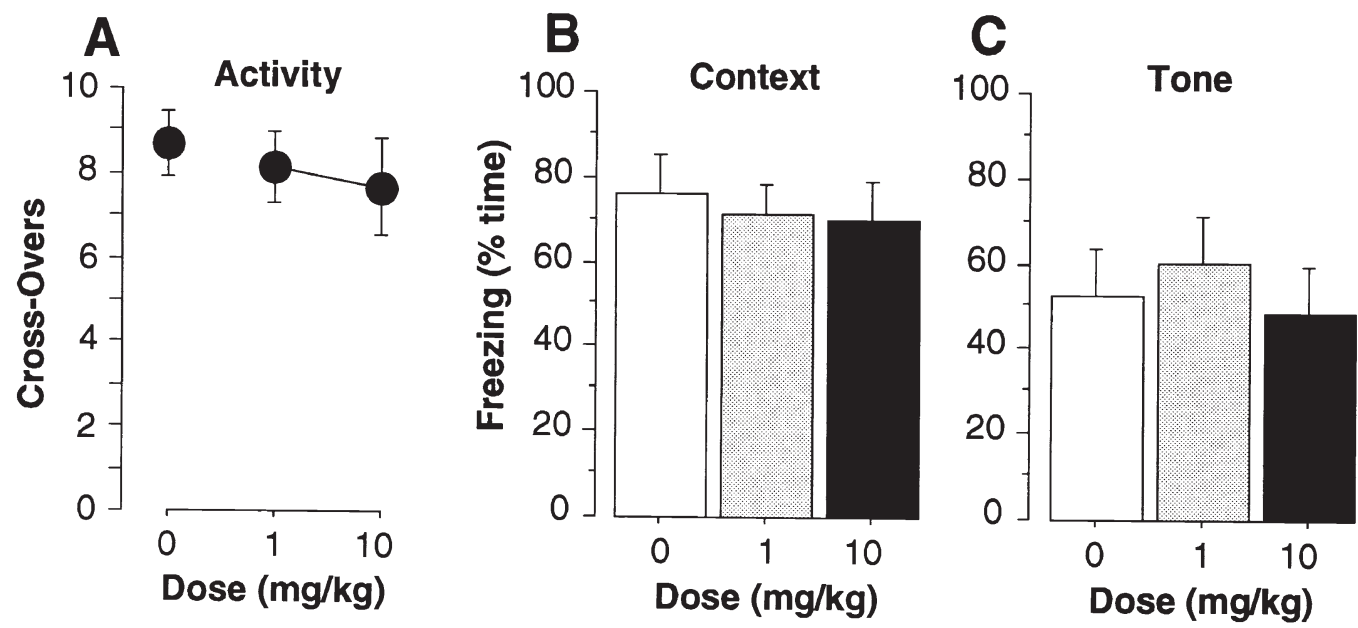

Figure 5. Experiment 2: Pretraining Methylscopolamine and Fear Conditioning. (A) Activity. Animals which received 0, 1, or $10 \mathrm{mg} / \mathrm{kg}$ ( $n=9-10 /$ group) methylscopolamine, i.p., 15-min prior to conditioning were scored for full-cage crossovers (mean \pm SEM) during the 3-min baseline period prior to the first tone-shock pairing. Methylscopolamine treated animals showed no evidence of hyperactivity, in contrast to those treated with scopolamine (Figure 1). (B) Context Conditioning. One week after training, the animals were returned to the original training context for a 4-min contextual freezing (mean \pm $\mathrm{SEM}$ ) test. Animals which received methylscopolamine on the training day did not differ from saline controls. (C) Tone Conditioning. One day after the context test, the animals were tested for freezing (mean \pm SEM) to a 4-min tone in a novel context. Methylscopolamine treated animals did not differ from saline controls. As such, all of the effects observed in Experiment 1 appear to be mediated by the central, rather than peripheral effects of scopolamine. 
(1991) who found hyperalgesia evidenced by reduced vocalization thresholds (albeit with a different shock source) and reduced tail-flick latencies at $1 \mathrm{mg} / \mathrm{kg}$ of scopolamine. Thus, depending on experimental conditions, scopolamine seems to produce no effect on pain sensitivity, as we observed (also Houser \& Hart, 1973), or hyperalgesia as others have observed (Grau et al., 1991; Watkins et al., 1984). In either case, the amnesic effects of scopolamine on learning cannot be attributed to decreased sensitivity to shock.

\section{Experiment 4: Post-Training Scopolamine and Fear Conditioning}

Because we have previously failed to observe any deficit in conditioning from $1 \mathrm{mg} / \mathrm{kg}$ of scopolamine given immediately (and for two more days) after training (Anagnostaras et al. 1995), we examined the effect of a much higher dose, $10 \mathrm{mg} / \mathrm{kg}$, given post-training. Figures $6 \mathrm{~A}-\mathrm{B}$ show that even this dose failed to produce any deficit in conditioning in adult rats. Separate univarate ANOVAs confirmed this observation for context $[F(2,26)=0.2, p>.8]$ and tone conditioning $[F(2,26)=0.3, p>.7]$.

The lack of retrograde amnesia from even $10 \mathrm{mg} / \mathrm{kg}$ of immediate post-training scopolamine is in some disparity with the findings of Rudy (1996), who found that one-tenth of this dose readily disrupted consolidation in 23-day-old rats. As such, Experiment 5 sought to determine if this effect was unique to immature rats.

\section{Experiment 5: Post-Training Scopolamine and Fear Conditioning in Juvenile and Mature Rats}

In Experiment 5, we examined the effect of 1 or $50 \mathrm{mg} /$ $\mathrm{kg}$ of immediate post-training scopolamine under reduced fear conditioning (relative to Experiments 1, 2, and 4) in 23-day-old (Juvenile) and 70-day-old (Mature) rats. It is obvious from examination of Figures $7 \mathrm{~A}$ and 7B that scopolamine failed to produce retrograde amnesia of context or tone fear at 1 or $50 \mathrm{mg} / \mathrm{kg}$. This was confirmed by separate $2 \times 3$ (age $\times$ dose) ANOVAs for context and tone conditioning. There was no age $X$ dose interaction for either context or tone fear $[F(2,66)<$ $0.3, p>$.7].

There was no main effect of drug dose for either measure $[F(2,66)<0.7, p>.5]$ nor any significant posthoc comparisons between drug dose groups within each age for either response $(p>.5)$. There was, however, a main effect of age, as Juvenile animals froze significantly more than Mature animals to either the context $[F(1,66)=18, p<.0001]$ or tone $[F(1,66)=14, p<$ .001]. However, this was at least partially accounted for by higher baseline freezing, which averaged $13.6 \pm$ $3.7 \%$ in Juvenile rats and $0.3 \pm 0.2 \%$ in Mature $\operatorname{rats}[F(1,70)=14, p<.001]$; baseline freezing was unaf-
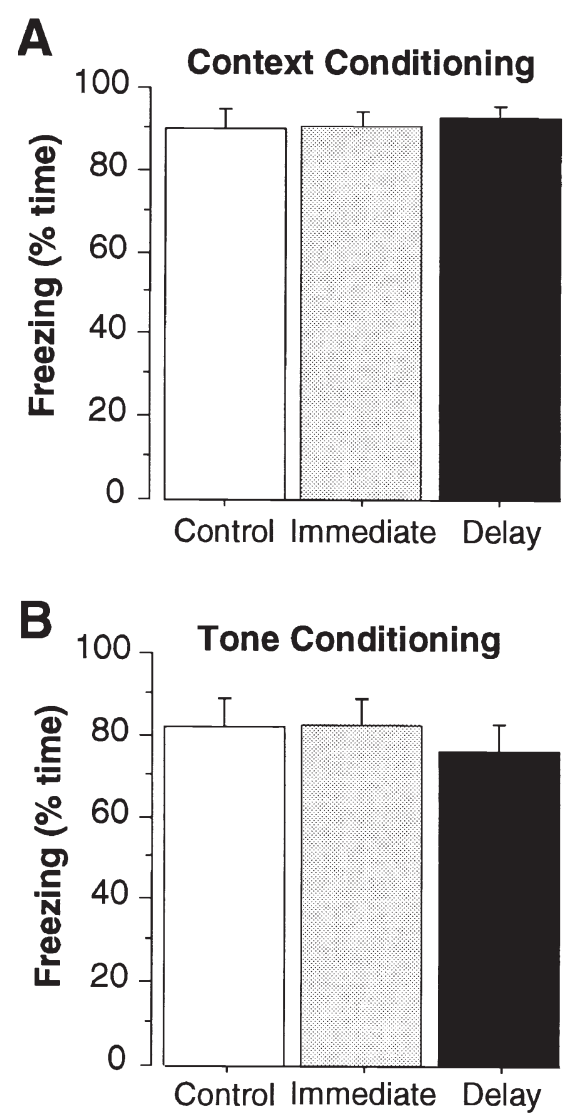

Figure 6. Experiment 4: Post-Training Scopolamine and Fear Conditioning. In order to assess the effect of posttraining scopolamine, animals received either saline (Control) or $10 \mathrm{mg} / \mathrm{kg}$ scopolamine either immediately (Immediate) or 24 hrs after (Delay) conditioning ( $n=9-10 /$ group). (A) Context Conditioning. One week after training, the animals were given a 4-min contextual freezing (mean \pm SEM) test. Rats treated with $10 \mathrm{mg} / \mathrm{kg}$ post-training scopolamine did not differ from saline controls. (B) Tone Conditioning. On the next day, animals were tested for their freezing (mean \pm $\mathrm{SEM}$ ) to a 4-min tone. Rats treated with post-training scopolamine did not differ from controls. As such, although 10 $\mathrm{mg} / \mathrm{kg}$ of pre-training scopolamine severely disrupted conditioning (Figure 3), the same dose of post-training scopolamine had virtually no effect.

fected by and did not interact with drug dose $[F(2,66)<$ $1.2, p>$.3]. As such, despite differences in the absolute amount of freezing observed in Juvenile and Mature animals (which may have many sources), it is clear that post-training scopolamine, even at doses of $50 \mathrm{mg} / \mathrm{kg}$ did not produce retrograde amnesia in Juvenile or Mature for context or tone fear conditioning.

It is unclear why we did not observe retrograde amnesia reported by Rudy (1996) with post-training i.p. injections of scopolamine. He observed an amnesia of contextual fear, under similar parameters, even when 1 $\mathrm{mg} / \mathrm{kg}$, s.c., was given up to $3 \mathrm{hrs}$ after training. It is clear that this difference was not simply due to the fact 

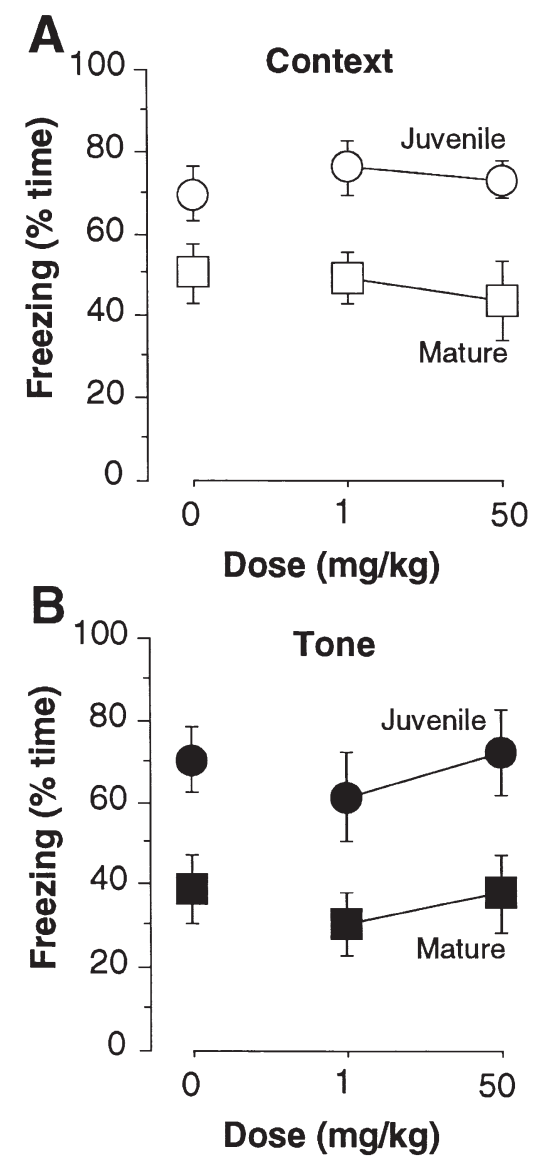

Figure 7. Experiment 5: Post Training Scopolamine and Fear Conditioning in Juvenile and Mature Rats. In order to determine if the apparent discrepancy with the findings of Rudy (1996) was due to his use of 23-day-old rats, we examined the effect of 1 and $50 \mathrm{mg} / \mathrm{kg}$ of immediate post-training scopolamine in 23-day-old (Juvenile) and 70-day-old (Mature) rats $(n=11-13 /$ cell). (A) Context Conditioning. One week after training, the animals were given a 4-min contextual freezing test (mean $\pm \mathrm{SEM}$ ). Although Juvenile rats froze significantly more than Mature rats, there was no significant impact of 1 or $50 \mathrm{mg} / \mathrm{kg}$ of post-training scopolamine on contextual fear in Juvenile or Mature rats. (B) Tone Conditioning. On the next day, animals were tested for their freezing to a 4-min tone. Juvenile rats again froze more than Mature rats, but this was apparently due to higher baseline freezing (data not shown). Neither 1 nor $50 \mathrm{mg} / \mathrm{kg}$ of post-training scopolamine produced a significant deficit in tone fear in Juvenile or Mature rats. As such, under the conditions in the present studies, we could not obtain post-training effects of scopolamine even at very high doses $(50 \mathrm{mg} / \mathrm{kg})$ given immediately after training, even in very young rats. We are not able to account for this discrepancy with Rudy (1996), although his findings indicate there are some conditions under which post-training scopolamine produces retrograde amnesia.

that he used 23-day-old rats, as we previously suggested (Anagnostaras et al. 1995). One possibility is that the level of fear in the present study was higher than in Rudy (1996) and that low levels of fear are more suscep- tible to post-training scopolamine (indeed, in Rudy's work, one training trial was more susceptible than 3 training trials). Another possibility is that s.c. scopolamine used by Rudy (1996) may have been active longer than the i.p. scopolamine we used, but this seems unlikely, as our high dose was fifty times higher. In any case, it is clear that anterograde amnesia induced by scopolamine is more robust and more readily observable than retrograde amnesia, at least under the high levels of fear used in the present studies (see also Rudy, 1996, Experiment 5). This is consistent with examinations of scopolamine's effects in a variety of other tasks, where amnesic effects from post-training scopolamine are not as consistently observed as the pervasive effects of pre-training administration (e.g., Aigner et al. 1991; Hagan et al. 1986)

\section{DISCUSSION}

At the behavioral level, Pavlovian fear conditioning involves the association of two types of conditional stimuli (the tone and context) with an aversive unconditional stimulus (US). Scopolamine might produce deficits in several fundamental processes: during conditioning, scopolamine could disrupt the animal's ability to process the US, to process the contextual and tone CSs, or to associate the CSs and US together. After training, scopolamine could disrupt the consolidation of the internalized memories of the US or CSs (i.e., the representations) or of the CS-US association. Based on the present data, it does not appear that scopolamine disrupts US processing or consolidation (c.f., Rudy, 1996) (see below), but pre-training scopolamine may attenuate the rat's ability to process the CSs or to associate them with the shock.

\section{Scopolamine Compared with Hippocampal Lesions}

It is sometimes claimed that the effects of anticholinergic action mimic those observed after hippocampal lesions (Watts et al. 1981). Moderate pre-training doses produce motor hyperactivity (Figure 1), attenuate postshock freezing (Figure 2), and produce robust and relatively selective deficits in contextual fear (Figures 3 and 4), much in the way hippocampal lesions do (Maren and Fanselow 1997; Phillips and LeDoux 1992). In contrast, post-training scopolamine had no impact on consolidation in the present study even when given at very high doses. Although post-training scopolamine may produce deficits under low levels of fear, a severe retrograde amnesia of contextual fear results from hippocampal lesions even after intensive training (Kim and Fanselow 1992; Anagnostaras et al. 1999). Even in Rudy's (1996) study, post-training scopolamine produced deficits when given up to $3 \mathrm{hrs}$, but not $24 \mathrm{hrs}$ af- 
ter training. In contrast, hippocampal lesions made even $1 \mathrm{wk}$ after training produce substantial deficits (Kim and Fanselow 1992; Maren et al. 1997).

Indeed, deficits observed when hippocampal lesions are made post-training are usually greater than those given pre-training (Maren et al. 1997, 1998), whereas the opposite appears to be true of scopolamine. As such, pretraining scopolamine (at moderate doses) seems to mimic the effects of hippocampal lesions, whereas posttraining scopolamine (at any dose) does not.

\section{Scopolamine Compared with Amygdala Lesions}

One possibility is that some of scopolamine's effects may be due to disruption of the amygdala. Lesions directed at the amygdala produce a severe anterograde amnesia of contextual and tone fear (Phillips and LeDoux 1992), as well as a severe, temporally-stable retrograde amnesia of both types of conditioning (Maren et al. 1996a). As such, scopolamine did not nearly have as great an effect as do lesions of the amygdala, even at $50-100 \mathrm{mg} / \mathrm{kg}$. Nonetheless, because of effects on tone conditioning, some scopolamine deficits may be through action in the amygdala, but this is not equivalent to amygdalar destruction.

\section{Scopolamine Compared with NMDA Receptor Antagonism}

Pre-training, but not post-training administration of $\mathrm{APV}$, which blocks the induction (but not expression) of LTP (Collingridge et al. 1983), blocks Pavlovian fear conditioning. Pre-training intra-cerebral, intra-hippocampal, or intra-amygdalar infusion of APV blocks contextual fear, whereas post-training administration does not (Kim et al. 1991; Fanselow et al. 1994; Young et al. 1994; Maren et al. 1996b; Kim et al. 1992; Campeau et al. 1992). Thus, the effects of scopolamine appear to be similar the effects of the NMDA receptor antagonist APV. These observations are consistent with the view that scopolamine may be disrupting acquisition processes similar to those for which NMDA receptor activation (and LTP) is required.

\section{Scopolamine and LTP}

Because it has been observed that LTP can be optimally induced in the hippocampus when presynaptic high frequency bursts are delivered at theta rhythm (Larson et al. 1986), there has been considerable speculation that cholinergic modulation of theta rhythm may be important to the induction of LTP (Huerta and Lisman 1995). Studies examining the role of scopolamine on LTP are somewhat mixed but cholinergic activation may be important under conditions of minimal or natural stimulation. Under stimulation that mimicked naturally occur- ring bursts in the hippocampus, Huerta and Lisman (1995) found an LTP that was blocked by either scopolamine or APV. Some have speculated that cholinergic activation of theta rhythm may enable LTP induction in concert with the activation of exploratory behavior, as these logically accompany one another (Buszáki and Gage 1991). Thus, it is possible that cholinergic neurotransmission plays a similar or complementary role to NMDA receptor transmission in the acquisition processes.

\section{Scopolamine and CS Processing}

Because scopolamine's effects were restricted to when the drug was given before training, one possibility is that scopolamine disrupts the acquisition of Pavlovian fear by disrupting the animal's ability to process, through sensory-perceptual disturbance, the context and tone cues that were paired with shock (e.g., Whishaw and Tomie 1987). Context conditioning may have been more sensitive to cholinergic disruption than tone conditioning, because contextual fear conditioning requires the integration of multiple sensory cues (i.e., visual, acoustic, olfactory, etc.) whereas tone conditioning requires the sampling of only one cue (e.g., Kim and Fanselow 1992; Rudy 1996; Anagnostaras et al. 1995). This is still somewhat similar to the role we have proposed for the hippocampus in contextual fear conditioning, which we have argued forms the contextual CS by assembling multiple cues into a single spatial or configural representation (Kim and Fanselow 1992; Young et al. 1994; Maren et al. 1998; Frankland et al. 1998; Anagnostaras et al. 1999). Nonetheless, ruling out the less exciting possibility that scopolamine produced deficits through purely sensory disturbance will require further investigation.

\section{CONCLUSIONS}

As such, the hippocampus, which mediates contextual conditioning, may be more readily impacted by scopolamine than the amygdala, which mediates fear more generally. At moderate doses, scopolamine produced effects somewhat similar to NMDA receptor antagonism, suggesting muscarinic neurotransmission may play a complementary role in the acquisition processes. Systemic scopolamine may have acted in the hippocampus to robustly disrupt contextual fear conditioning, and in the amygdala to attenuate tone conditioning at high doses. Because the drug was given systemically, many other interpretations are possible and studies are in progress examining the effects of site-specific administration of scopolamine. In preliminary studies examining local pre-training administration of scopolamine 
to the hippocampus we have found a disruption of context, but not tone conditioning (Gale et al. 1998).

Finally, the present findings further bind together contextual fear conditioning the hidden-platform Morris water maze and "win-shift" radial maze learning in rats. All three tasks are disrupted by lesions of the hippocampus or NDMA receptor antagonism (Kim and Fanselow 1992; Anagnostaras et al. 1999; Kim et al. 1991; Morris et al. 1986; Kawabe et al. 1998) all three exhibit sexual dimorphism (Maren et al. 1994b; Anagnostaras et al. 1998; Williams and Meck 1991), and recent evidence indicates similar targeted mutations in mice disrupt these tasks (e.g., Lu et al. 1997). The present report confirms that contextual fear conditioning, like the water (Hagan et al. 1986) and radial (Levin et al. 1990) mazes, is also sensitive to cholinergic disruption. While the relative sensitivity to scopolamine of the hippocampal dependent and independent versions of these tasks remains in considerable dispute (e.g., Hagan et al. 1986), there is at least some consensus that the hippocampal versions are more sensitive. Thus, although these tasks are very different in nature, they seem to be served by common mechanisms.

In summary, scopolamine dose-dependently disrupted the acquisition, but not the consolidation, of contextual fear conditioning, a hippocampal-dependent form of learning. The effects were somewhat similar to NMDA receptor antagonism, suggesting that cholinergic neurotransmission plays a similar or complementary role in the acquisition processes. Further study is necessary to determine the loci of scopolamine's effects and the exact conditions under which post-training scopolamine may produce retrograde amnesia.

\section{ACKNOWLEDGMENTS}

This research was supported by NSF grant (IBN 9723295) to MSF. S.A. was supported by UCLA CM Kernan Dissertation Year Fellowship. S.M. was supported by an individual NIMH National Research Service Award (MH11061). An earlier version of this manuscript was part of S.A.'s UCLA doctoral dissertation. We thank Drs. Bernard Balleine, Barbara Knowlton, Frank Krasne, Tom O'Dell, Terry Robinson, and Jerry Rudy for their thoughtful comments on an earlier version of this manuscript. NIH Image is available on the world wide web at http://rsb.info.nih.gov/NIH-image.

\section{REFERENCES}

Aigner TG, Walker DL, Mishkin M (1991): Comparison of the effects of scopolamine administered before and after acquisition in a test of visual recognition in monkeys. Behav Neural Biol 55:61-67

Amaral DG, Kurz J (1985): An analysis of the origins of the cholinergic and noncholinergic septal projections to the hippocampal formation in the rat. J Comp Neurol 240:37-59

Anagnostaras SG, Maren S, Fanselow MS (1999): Temporally-graded retrograde amnesia of contextual fear after hippocampal damage in rats: Within-subjects examination. J Neurosci 19:1106-1114

Anagnostaras SG, Maren S, Fanselow MS (1995): Scopolamine selectively disrupts the acquisition of contextual fear conditioning in rats. Neurobiol Learn Memory 64:191-194

Anagnostaras SG, Maren S, DeCola JP, Lane NI, Gale GD, Schlinger BA, Fanselow MS (1998): Testicular hormones do not regulate sexually dimorphic Pavlovian fear conditioning or perforant-path long-term potentiation in adult male rats. Behav Brain Res 92:1-9

Brown JH (1993): Atropine, scopolamine, and related antimuscarinic drugs. In Goodman AG, Rall TW, Nies AS, Taylor P (eds), Goodman and Gilman's Pharmacological Basis of Therapeutics, 8th ed. New York, McGrawHill, pp 150-165

Buszáki G, Gage FH (1991): Long-term potentiation: Does it happen in the normal brain? When and how? In Abraham WC, Corballis MC, White KG (eds), Memory Mechanisms: A tribute to G.V. Goddard. Hillsdale, NJ, Erlbaum, pp 79-104

Campeau S, Miserendino MJD, Davis M (1992): Intraamygdala infusion of the N-methyl-D-aspartate receptor antagonist APV blocks acquisition but not expression of fear-potentiated startle to an auditory conditioned stimulus. Behav Neurosci 106:569-574

Collingridge GL, Kehl S, McLennan H (1983): Excitatory aminoacids in synaptic transmission in the Schaffer collateral-commisural pathway of the rat hippocampus. J Physiol 334:33-46

Crow T, Grove-White I (1973): An analysis of the learning deficit following hyoscine administration in man. Br J Pharmacol 49:322-327

Davis M (1986): Pharmacological and anatomical analysis of fear conditioning using the fear-potentiated startle paradigm. Behav Neurosci 100:814-824

Fanselow MS, Bolles RC (1979): Naloxone and shock-elicited freezing in the rat. J Comp Physiol Psychol 93:736-744

Fanselow MS, Kim JJ, Yipp J, DeOca B (1994): Differential effects of N-methyl-D-aspartate antagonist DL-2amino-5-phosphonovalerate on acquisition of fear of auditory and contextual cues. Behav Neurosci 108:235240

Frankland PW, Cestari V, Filipkowski RK, McDonald RJ, Silva AJ (1998): The dorsal hippocampus is essential for context discrimination but not for contextual conditioning. Behav Neurosci 112:1-12

Gale GD, Anagnostaras SG, Fanselow MS (1998): Cholinergic modulation of Pavlovian fear conditioning: Selective disruption of contextual conditioning by intrahippocampal infusion of scopolamine. Soc Neurosci Abstr 24:1904

Godsil BP, Spooner JR, Anagnostaras SG, Gale GD, Fanselow MS (1997): Quantification of the unconditional response to footshock in the rat: Measurement of the activity burst with the use of computer-based image analysis. Soc Neurosci Abstr 23:1612 
Grau JW, Illich PA, Chen PS, Meagher MW (1991): Role of cholinergic systems in pain modulation. I. Impact of scopolamine on environmentally induced hypoalgesia and pain reactivity. Behav Neurosci 105:62-81

Hagan JJ, Tweedie F, Morris RGM (1986): Lack of task specificity and absence of posttraining effects of atropine on learning. Behav Neurosci 100:483-493

Harvey JA, Gormezano I, Cool-Hauser VA (1983): Effects of scopolamine and methyl scopolamine on classical conditioning of the rabbit nictitating membrane response. J Pharmacol Exp Therap 225:42-49

Houser VP, Hart DAV (1973): Modulation of cholinergic activity and aversive threshold in the rat. Pharmacol Biochem Behav 2:631-637

Huerta PT, Lisman JE (1995): Bidirectional synaptic plasticity induced by a single burst during cholinergic theta oscillation in CA1 in vitro. Neuron 15:1053-1063

Kawabe K, Ichitani Y, Iwasaki T (1998): Effects of intrahippocampal AP5 treatment on radial-arm maze performance in rats. Brain Res 781:300-306

Kim JJ, Fanselow MS (1992): Modality-specific retrograde amnesia of fear. Science 256:675-677

Kim JJ, DeCola JP, Landeira-Fernandez J, Fanselow MS (1991): N-methyl-D-aspartate receptor antagonist APV blocks acquisition but not expression of fear conditioning. Behav Neurosci 105:126-133

Kim JJ, DeCola JP, Landeira-Fernandez J, Fanselow MS (1992): Selective impairment of long-term but not shortterm conditional fear by the N-methyl-D-aspartate antagonist APV. Behav Neurosci 106:591-596

Larson J L, Wong D, Lynch G (1986): Patterned stimulation at the theta frequency is optimal for the induction of hippocampal long-term potentiation. Brain Res 368: 347-350

Levin ED, McGurk SR, Rose JE, Butcher LL (1990): Cholinergic-dopaminergic interactions in cognitive performance. Behav Neural Biol 54:271-299

Lu Y, Jia Z, Janus C, Henderson JT, Gerlai R, Wojtowicz JM, Roder JC (1997): Mice lacking metabotropic glutamate receptor 5 show impaired learning and reduced CA1 long-term potentiation (LTP) but normal CA3 LTP. J Neurosci 17:5196-205

Maren S, Fanselow MS (1997): Electrolytic lesions of the dorsal hippocampus, fimbria-fornix, or entorhinal cortex produce anterograde deficits in contextual fear conditioning in rats. Neurobiol Learn Memory 67:142-149

Maren S, Aharonov G, Fanselow MS (1996a): Retrograde abolition of conditional fear after excitotoxic lesions of the basolateral amygdala of rats: Absence of temporal gradient. Behav Neurosci 110:718-726

Maren S, Aharonov G, Fanselow MS (1997): Neurotoxic lesions of the dorsal hippocampus and Pavlovian fear conditioning in rats. Behav Brain Res 88:261-274

Maren S, Aharonov G, Stote DL, Fanselow MS (1996b): $\mathrm{N}$-methyl-D-aspartate receptors in the basolateral amygdala are required for both the acquisition and expression of conditional fear in rats. Behav Neurosci 110:1365-1374

Maren S, Anagnostaras SG, Fanselow MS (1998): The startled seahorse: Is the hippocampus necessary for contextual fear conditioning? Trends Cogn Sci 2:39-42
Maren S, DeCola JP, Swain RA, Fanselow MS, Thompson RF (1994a): Parallel augmentation of hippocampal longterm potentiation, theta rhythm, and contextual fear conditioning in water-deprived rats. Behav Neurosci 108:44-56

Maren S, DeOca B, Fanselow MS (1994b): Sex differences in hippocampal long-term potentiation (LTP) and Pavlovian fear conditioning in rats: Positive correlation between LTP and contextual learning. Brain Res 661:25-34

Mathur A, Shandarin A, LaViolette SR, Parker J, Yeomans JS (1997): Locomotion and stereotypy induced by scopolamine: Contributions of muscarinic receptors near the pedunculopontine tegmental nucleus. Brain Res 775: 144-155

Morris RGM, Anderson E, Lynch GS, Baudry M (1986): Selective impairment of learning and blockade of longterm potentiation by an N-methyl-D-aspartate receptor antagonist, AP5. Nature 319:774-776

Nies AS (1993): Principles of therapeutics. In Goodman AG, Rall TW, Nies AS, Taylor P (eds), Goodman and Gilman's Pharmacological Basis of Therapeutics, 8th ed. New York, McGraw-Hill, pp 62-83

Overton DA (1966): State-dependent learning produced by depressant and atropine-like drugs. Psychopharmacologia 10:6-31

Paylor R, Rudy JW (1990): Cholinergic receptor blockade can impair the rat's performance on both the place learning and cued versions of the Morris water task: The role of age and pool wall brightness. Behav Brain Res 36:79-90

Phillips RG, LeDoux JE (1992): Differential contribution of amygdala and hippocampus to cued and contextual fear conditioning. Behav Neurosci 106:274-285

Rudy JW (1996): Scopolamine administered before and after training impairs both contextual and auditory-cue fear conditioning. Neurobiol Learn Memory 65:73-81

Vanderwolf CH, Kramis R, Robinson TE (1978): Hippocampal electrical activity during waking behaviour and sleep: Analysis using centrally acting drugs. In Elliot K, Whelan J (eds), Functions of the Septo-Hippocampal System. Amsterdam, The Netherlands, Elsevier, pp 199-221

Watkins LR, Katayama Y, Kinscheck IB, Mayer DJ, Hayes RL (1984): Muscarinic cholinergic mediation of opiate and non-opiate environmentally induced analgesia. Brain Res 300:231-242

Watts J, Stevens R, Robinson C (1981): Effects of scopolamine on radial maze performance in rats. Physiol Behav 26: 845-851

Whishaw IQ, Tomie J (1987): Cholinergic receptor blockade produces impairments in a sensorimotor subsystem for place navigation in the rat: Evidence from sensory, motor, and acquisition tests in a swimming pool. Behav Neurosci 101:603-616

Williams CL, Meck WH (1991): The organizational effects of gonadal steroids on sexually dimorphic spatial ability. Psychoneuroendocrinology 16:155-176

Young SL, Bohenek DL, Fanselow MS (1994): NMDA processes mediate anterograde amnesia of contextual fear conditioning induced by hippocampal damage: Immunization against amnesia by context preexposure. Behav Neurosci 108:19-29 